\title{
IMPLEMENTASI LOGIKA FUZZY DENGAN INFERENSI TSUKAMOTO PADA DETEKSI KEGAGALAN SISTEM TRANSFER CAKE BREAKER CONVEYOR (CBC)
}

\author{
1)Alkadri Masnur, ${ }^{2)}$ M.Khairul Anam \\ 1),2) STMIK Amik Riau Program Studi Teknik Informatika \\ Jl.Purwodadi Indah Km.10,5 Panam Pekanbaru \\ E-Mail : alkadrimasnur@stmik-amik-riau.ac.id,khairulanam@stmik-amik-riau.ac.id
}

\begin{abstract}
ABSTRAK
Pabrik Kelapa Sawit merupakan industri bahan baku yang mengolah tandan buah segar (TBS) kelapa sawit menjadi CPO (Crude Palm Oil) minyak mentah kelapa sawit. Satu Unit Pabrik Kelapa Sawit memiliki stasiun kempa/press, lebih spesifik pada motor transfer (cangkang dan ampas kelapa sawit). Untuk 1 unit Cake Breaker Conveyor (CBC) dengan panjang 30 meter, melayani 4 mesin press. Ampas dan cangkang kelapa sawit yang akan ditransfer masih berupa gumpalan padat akibat proses pengepresan dan memiliki suhu 98oC, dengan beban yang relatif berat dan suhu yang tinggi maka screw CBC sering mengalami kegagalan transfer akibat putusnya As Screw. Jika terjadi kegagalan transfer maka cangkang dan ampas kelapa sawit akan menumpuk pada titik pembuangan mesin press, selain itu umpan bahan bakar boiler tergangu karena cangkang dan ampas kelapa sawit tidak terkirim ke tungku bahan bakar. Untuk menentukan titik putusnya As Screw pada posisi yang tepat diperlukan sebuah metode yang dapat menemukan putusnya As-screw pada unit CBC. Logika Fuzzy Tsukamoto dapat membantu memperhitungkan dimana titik As-screw putus pada CBC, dengan menggunakan input waktu dan kecepatan putaran motor CBC deteksi menggunakan rotary encoder, output yang digunakan adalah titik dimana As-screw putus pada CBC sepanjang 30 meter. Penelitian ini diharapkan menjadi salah satu solusi untuk mengatasi permasalahan yang terjadi pada pabrik kelapa sawit khususnya pada stasiun kempa.
\end{abstract}

Kata kunci: Cake Breaker Conveyor,CBC, As-Screw, Fuzzy Tsukamoto

\begin{abstract}
The palm Oil Factory is a raw material industry that processes Fresh Fruit Bunches (FFB) into Crude Palm Oil (CPO). Palm oil Factory has a press station in press station has unit Cake Breaker Conveyor (CBC). The CBC to use to transfer dregs and palm shells as fuel bait. For one unit CBC can be serving 4 press machines the waste and oil palm shells to be transferred are still solid clumps due to pressing process is have temperature of $980 C$. In addition to the high temperatures of the dregs and the palm oil shells are dense clumps that cause transfer failure In case of transfer failure, the shell and the oil palm dregs will accumulate at the point of disposal of the press machine, other than that the boiler fuel feed is disturbed because the shells and the oil palm dregs are not sent to the fuel furnace. To determine the As Screw break point in the proper position required a method that can find As-screw breaks on the CBC unit. The Fuzzy Tsukamoto logic can help calculate where the $A s$-screw point breaks on the $C B C$, using the input time and rotation speed of the $C B C$ detection motor using the rotary encoder, the output used is the point where As-screw breaks on a 30 meters. This research is expected to be one solution to solve the problems that occur in the palm oil mill especially in the press station.
\end{abstract}

Keywords: Cake Breaker Conveyor, As-Screw, Fuzzy Tsukamoto

\section{PENDAHULUAN}

Propinsi Riau adalah salah satu propinsi didaerah sumatra yang dijadikan sentra perkebunan sawit, selain propinsi sumatra utara. perkebunan kelapa sawit adalah, industri tanaman perkebunan yang menghasilkan Tandan Buah Segar (TBS) kelapa sawit. Kelapa sawit dapat bermanfaat bagi masyarakat maka dibutuhkan pengolahan TBS kelapa sawit menjadi Crude Palm Oil (CPO) atau minyak mintah kelapa sawit.
Minyak mentah kelapa sawit memiliki kandungan mineral alami, menurut (Kimia, Teknik, \& Surabaya, n.d.) komponen utama CPO adalah Trigliserida dengan kandungan 93\% kandungan gliserida yang lain dalam CPO adalah digliserida $4,5 \%$ dan monolgriserida 0,9 \%. Pabrik kelapa sawit memiliki proses pengolahan , Menurut (Kimia et al., n.d.) proses pengolahan kelapa sawit dari tandan buah segar (TBS) hingga dihasilkan CPO dan inti sawit 
melalui beberapa stasiun pengolahan yang dapat dibagi menjadi 3 tahapan sebagai berikut:

a. Tahapan Pengolahan Awal

1) Stasiun Penerimaan Buah

2) Stasiun Rebusan (Sterilizer)

3) Stasiun Penebah

4) Stasiun Kempa

b. Tahapan Pengolahan CPO

1) Stasiun Klarifikasi

2) Stasiun Penimbunan Minyak

3) Stasiun Pengutipan Minyak

c. Tahapan Pengolahan Inti Sawit

1) Stasiun Defricarper

2) Stasiun Pabrik Biji

Untuk meningkatkan jumlah produksi manajemen produksi akan memilah prosedur atau proses yang menghambat peningkatan produksi. Permasalah yang sering dihadapi pada proses pemisahan ampas dengan inti kelapa sawit terdapat pada transfer CBC (Cake Breaker Conveyor). Pada pabrik kelapa sawit kapasitas 30 ton/jam memiliki 1 unit $\mathrm{CBC}$ sedangkan pada pabrik kelapa sawit kapasitas 60 ton/jam memiliki 2 unit CBC. Setiap 1 unit $\mathrm{CBC}$ memiliki panjang 30 meter untuk melayani 4 mesin press yang akan mentransfer ampas kelapa sawit tersebut ke stasiun bahan bakar boiler. Menurut (Okafor, 2015) Suhu ampas kelapa sawit sebelum dilakukan pemisahan sekitar $98^{\circ} \mathrm{C}$ suhu ini didapat dari proses digester, jika unit Screw putus atau terjadi kegagalan pada transfer maka ampas kelapa sawit yang dikeluarkan dari mesin press akan menumpuk pada masing - masing terminal press, dan menghambat proses pengiriman bahan bakar ke boiler yang akan berdampak berhentinya pabrik, untuk mengatasi permasalahan tersebut dibutuhkan waktu 3 jam sampai dengan 4 jam untuk memperbaiki $\mathrm{CBC}$ tersebut agar berjalan normal kembali.

\section{Sistem Inferensi Fuzzy Tsukamoto}

Menurut (Rohayani., 2015) Metode Tsukamoto adalah perluasan dari penalaran monoton. Pada metode Tsukamoto, setiap konsekuen pada aturan yang berbentuk IF-THEN harus direpresentasikan dengan suatu himpunan fuzzy dengan fungsi keangotaan yang monoton.

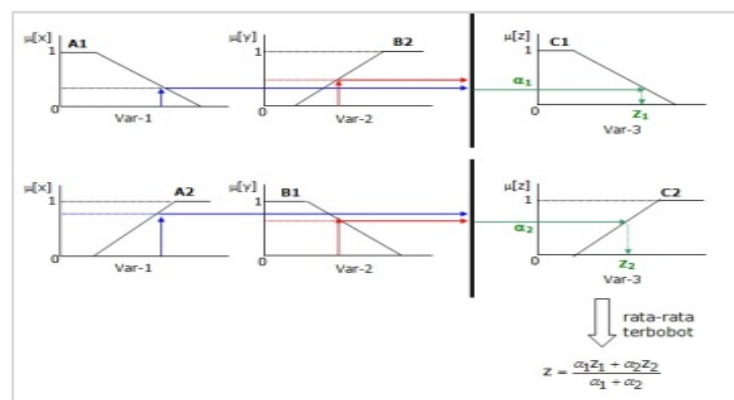

Gambar 1. Inferensi dengan menggunakan metode Fuzzy Tsukamoto

\section{Cake Breaker Conveyor (CBC)}

Cake Breaker Conveyor berfungsi untuk memecah gumpalan ampas hasil pengempaan(Press) buah sawit dan mengangkutnya ke dalam fiber cyclone. adalah suatu unit sistem yang memiliki motor pengerak, Screw Coveyor ( ulir dan poros) dan sistem transmisi, unit CBC pada pabrik kelapa sawit memiliki 4 unit masukan yang digunakan untuk melayani 4 unit mesin press dan 1 unit keluaran yang digunakan untuk melakukan transfer ampas dan biji kelapa sawit pada stasiun proses berikutnya. Menurut (Adhar, Sumarlan, \& Nugroho, 2015) Bagian-bagian pokok dari model metering device tipe screw conveyor dengan dua adalah screw conveyor, hopper, sistem transmisi, pengatur inlet dan outlet. Unit screw conveyor dapat dilihat pada gambar 1 dan bagian-bagian dari 1 unit screw conveyor dapat dilihat pada gambar 2 .

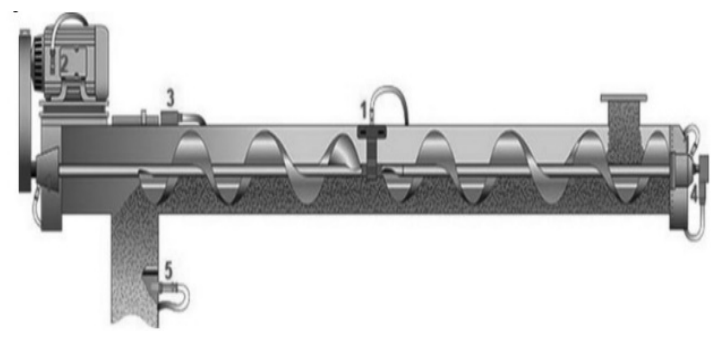

Gambar 2. Screw Conveyor (Santanu Chakarborthy1, 2014) 


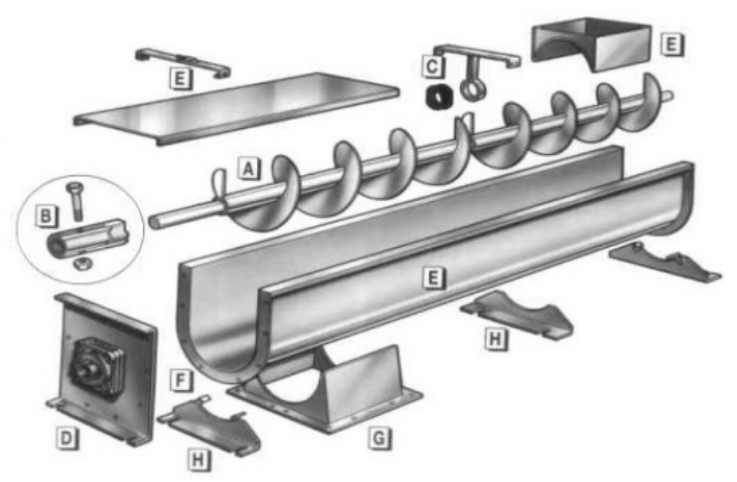

Gambar 3. Bagian-bagian Screw Conveyor (Wable \& Kurkute, 2015)

Pada gambar 3 ditunjukan bagian-bagian dari sebuah screw conveyor yang umum digunakan pada industri bahan baku sebagai suatu sistem yang digunakan untuk melakukan transfer bahan baku adapun rinci dari bagian screw conveyor dapat dilihat pada tabel 1 .

Tabel 1. Bagian-bagian Screw Conveyor(Wable \& Kurkute, 2015)

\begin{tabular}{ccl}
\hline No & Bagian & \multicolumn{2}{c}{ Fungsi } \\
\hline 1 & A & Ulir (Conveyor Screw) \\
\hline 2 & B & $\begin{array}{l}\text { Job-Rated Components Jig- } \\
\text { Drilled Couplings, Tem-ULac } \\
\text { Self-Locking Coupling Bolts }\end{array}$ \\
\hline 3 & C & Hangers and Bearings \\
\hline 4 & D & Trough Ends \\
\hline 5 & E & $\begin{array}{l}\text { Troughs, Covers, Clamps and } \\
\text { Shrouds }\end{array}$ \\
\hline 6 & F & Nu-Weld $®$ Flange \\
\hline 7 & G & Feed and Discharge Spouts \\
\hline 8 & H & Supporting Feet and Saddle \\
\hline
\end{tabular}

\section{Rotary Encoder}

Suatu sensor yang digunakan untuk mendeteksi posisi putaran, perpindahan dan kecepatan putaran dari sebuah motor yang bergerak. Menurut (Santoso, Puspita, Eru Kom, \& Akbar, Ressa Ccna, 2010) Rotary Encoder adalah komponen elektromekanik yang dapat memonitor gerakan dan posisi. Rotary Encoder umumnya menggunakan sensor optik untuk menghasilkan serial pulsa yang dapat diartikan menjadi gerakan, posisi,dan arah. Sehingga posisi sudut suatu poros benda berputar dapat diolah menjadi informasi berupa kode digital oleh Rotary Encoder untuk diteruskan oleh rangkaian kendali. Prinsip kerja Rotary Encoder dengan memanfaatkan photo sensor dan led yang melintasi lubang pada lempengan yang berada pada Rotary Encoder dapat dilihat pada gambar 4.

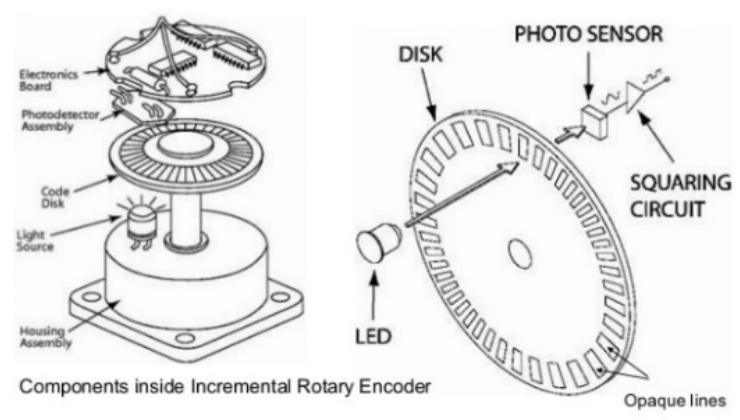

Gambar 4. Components Icremental Rotary Encoder

\section{METODE}

Metode penelitian yang dilakukan menggunakan Framework yang ditunjukan pada gambar 5 .

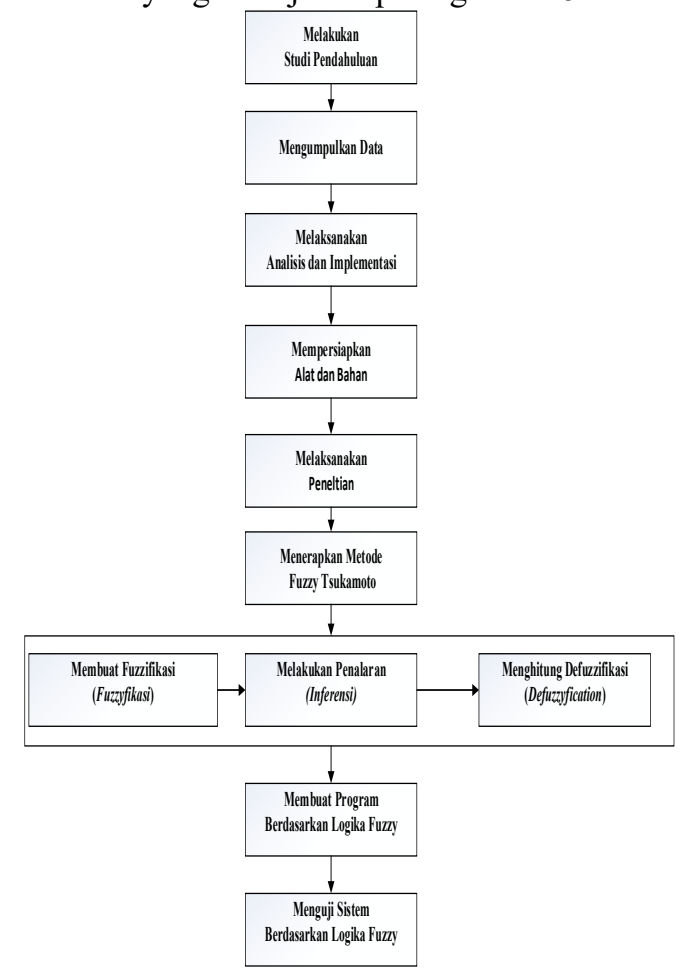

Gambar 5. Framework Penelitian

\section{HASIL}

1. Fuzzyfikasi variabel input dan output

Variabel yang digunakan untuk variable input yaitu kecepatan putaran motor CBC dan waktu deteksi yang didapat dari rotary encoder sedangkan veriabel output adalah titik ulir pada CBC sepanjang 30 Meter.

a. Variable Kecepatan Putaran Motor CBC 


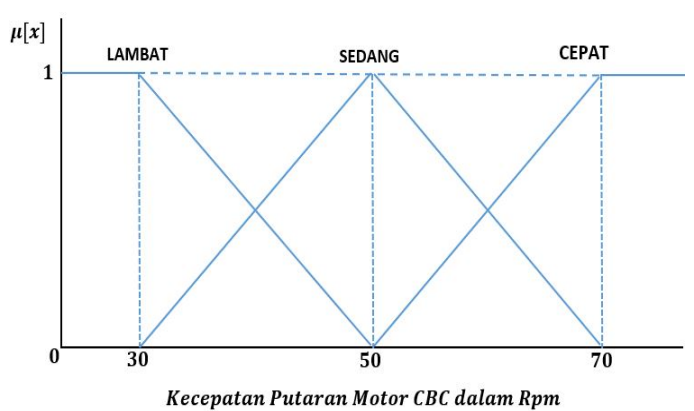

Gambar 6. Keanggotaan Putaran Motor CBC

$$
\begin{gathered}
\mu_{\mathrm{Xs}}(x)\left\{\begin{array}{lc}
1 & ; 0 \leq x \leq 30 \\
(50-x) /(50-30) & ; 30<x<50 \\
0 & ; x \geq 50
\end{array}\right. \\
\mu \mathrm{Ms}(x) \begin{cases}(x-30) /(50-30) & ; 30<x<50 \\
1 & ; x=50 \\
(70-x) /(70-50) & ; 50<x<70 \\
0 & ; x \leq 30 \text { ataux } x \geq 70\end{cases} \\
\mu_{\mathrm{ME}}(x) \begin{cases}0 & ; x \leq 50 \\
0 & ; 50<x<70 \\
(x-50) /(70-50) & ; x \geq 70 \\
1 & \end{cases}
\end{gathered}
$$

b. Variabel Waktu Deteksi Rotary Encoder

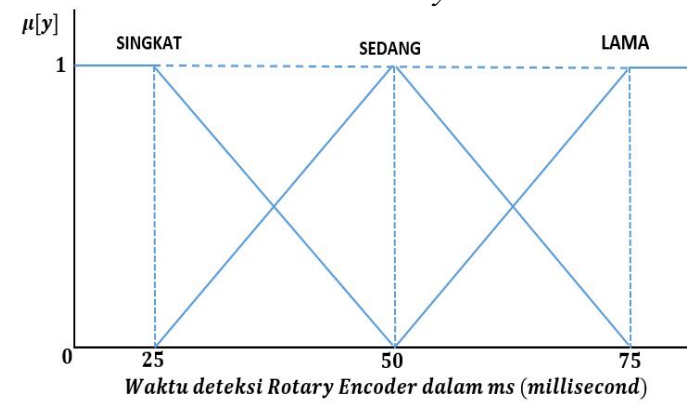

Gambar 7. Keanggotaan Waktu Deteksi Rotary Encoder

$$
\begin{aligned}
& \left.\mu_{\mathrm{Li}^{\prime}}(y)\right)\left(\begin{array}{l}
1 \\
(50-y) /(50-25) \\
0
\end{array}\right. \\
& \mu_{\mathrm{zr}}(y)\left\{\begin{array}{l}
(y-25) /(50-25) \\
1 \\
(75-y) /(75-25) \\
0
\end{array}\right. \\
& \mu_{I}(y)\left\{\begin{array}{l}
0 \\
(y-50) /(75-50) \\
1
\end{array}\right. \\
& \begin{array}{l}
; 0 \leq y \leq 25 \\
; 25<y<50 \\
; y \geq 50
\end{array} \\
& \text {; } 25<y<50 \\
& i y=50 \\
& \text { 1 } 50<y<75 \\
& \text { y } y \leq 25 \text { atau } y \geq 75 \\
& y \leq 50 \\
& \text {; } 50<y<75 \\
& \text { is } y \geq 75
\end{aligned}
$$

c. Variabel Output posisi deteksi pada ulir Cake breaker conveyor $(C B C)$

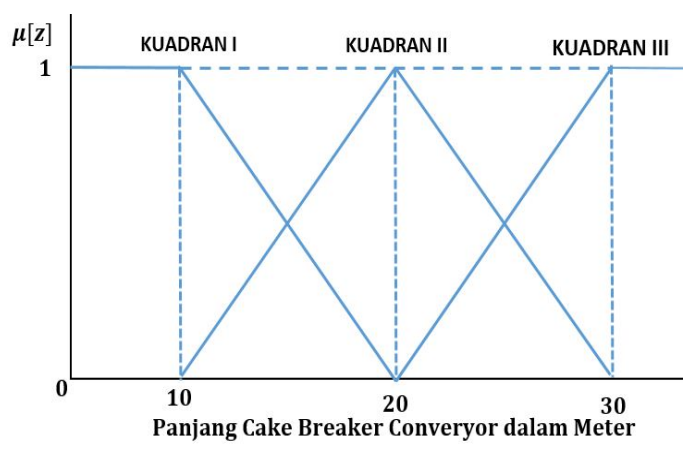

Gambar 8. Keanggotaan Panjang Cake Breaker Conveyor

$$
\begin{aligned}
& \mu_{z z}(z)\left\{\begin{array}{lc}
1 & ; 0 \leq z \leq 10 \\
(20-z) /(20-10) & i 10<z<20 \\
0 & i y \geq 20
\end{array}\right. \\
& \mu_{z z}(z) \begin{cases}(z-10) /(20-10) & ; 10<z<20 \\
1 & ; z=20 \\
(30-z) /(30-20) & ; 20<z<30 \\
0 & ; z \leq 10 \text { atau } z \geq 30\end{cases} \\
& \mu_{z m}(z) \begin{cases}0 & i y \leq 20 \\
(z-20) /(30-20) & ; 20<y<30 \\
1 & i y \geq 30\end{cases}
\end{aligned}
$$

\section{Penetuan rules}

Rules dibuat sebagai aturan atau metode yang harus diikuti variable fuzzy yang telah selesai ditetapkan. Rules yang dibuat menggunakan logika fuzzy Tsukamoto untuk menentukan titik kegagalan sistem transfer Cake Breaker Conveyor (CBC) adalah sebagai berikut :

[R1] If Putaran Motor Lambat And Deteksi Rotary Singkat Then Kuadran I

[R2] If Putaran Motor Sedang And Deteksi Rotary Singkat Then Kuadran I

[R3] If Putaran Motor Cepat And Deteksi Rotary Singkat Then Kuadran I

[R4] If Putaran Motor Lambat And Deteksi Rotary Sedang Then Kuadran I

[R5] If Putaran Motor Sedang And Deteksi Rotary Sedang Then Kuadran II

[R6] If Putaran Motor CepatAnd Deteksi Rotary Sedang Then Kuadran II

[R7] If Putaran Motor Lambat And Deteksi Rotary Lama Then Kuadran II

[R8] If Putaran Motor SedangAnd Deteksi Rotary Lama Then Kuadran III

[R9] If Putaran Motor Cepat And Deteksi Rotary Lama Then Kuadran III 


\section{Penegasan (Defuzzification)}

Penegasan atau defuzzifikasi adalah penentuan nilai tegas yang dihitung berdasarkan jumlah nilai predikat dikalikan dengan nilai rules dibagi jumlah predikat. Menggunakan rumus sebagai berikut :

$$
\begin{aligned}
& (a 1 * z 1+a z * z 2+a 3 * z 3+a 4 * z 4+a 5 * z 5+a 6 * z 6+ \\
& z=\frac{a 7 * 27+a 8 * 28+a 9 * 29)}{a 1+a 2+a 3+a 4+a 5+a 6+a 7+a 8+a 9}
\end{aligned}
$$

4. Pengolahan data menggunakan Fuzzy dengan Inferensi Tsukamoto

Pengolahan data menggunakan Fuzzy Tsukamoto pada putaran motor cbc 40rpm dan waktu deteksi encoder $65 \mathrm{~ms}$. Pada meter keberapakah terjadi kegagalan transfer $\mathrm{CBC}$ tersebut?

a. Fuzzyfikasi pada putaran motor CBC 40 rpm

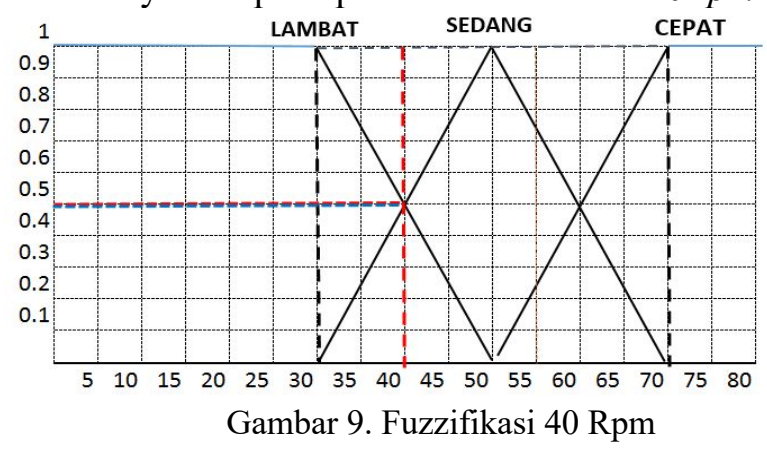

Nilai pada Motor Lambat $=0,5$

Motor Sedang $=0,5$

Motor Cepat $=0,0$

b. Fuzzifikasi Deteksi Waktu Rotary Encoder $65 m s$

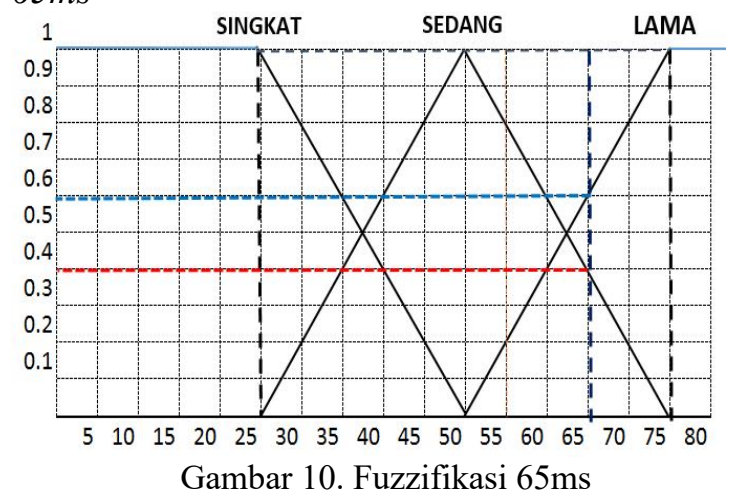

Nilai waktu deteksi

Rotary Encoder Singkat $=0,0$

$$
\text { Sedang }=0,4
$$$$
\text { Lama }=0,6
$$

$[\mathrm{R} 2] \alpha 2=0 \quad$ rules $=20$

$[\mathrm{R} 3] \alpha 3=0 \quad$ rules $=20$

$[\mathrm{R} 4] \alpha 4=0.4$ rules $=16$

$[\mathrm{R} 5] \alpha 5=0.4$ rules $=20$

$[\mathrm{R} 6] \alpha 6=0 \quad$ rules $=20$

$[\mathrm{R} 7] \alpha 7=0.50$ rules $=20$

$[\mathrm{R} 8] \alpha 8=0.50$ rules $=25$

$[\mathrm{R} 9] \alpha 9=0 \quad$ rules $=20$

d. Penegasan (Defuzzyfikasi)

$$
\begin{gathered}
z=\frac{(0 * 20+0 * 20+0 * 20+0,4 * 16+0,4 * 20+}{0 * 20+0,5 * 20+0,5 * 25+0 * 20)} \\
0+0+0+0,4+0,4+0+0,5+0,5+0 \\
z=\frac{36,90}{1,80}=20,50 \text { meter }
\end{gathered}
$$

Hasil penelusuran pengolahan data menggunakan logika fuzzy dengan system inferensi Tsukamotor didapatkan hasil system mengalami gagal transfer pada titik 20,50 meter atau terletak pada kudran II.

5. Perhitungan menggunakan aplikasi berbasis desktop

Aplikasi deteksi titik putusnya screw-as CBC dibangun menggunakan Program Visual basic, menggunakan bahasa pemrograman basic dan penerapan logika fuzzy dengan system inferensi Tsukamoto. Tolok ukur pengujian aplikasi yang akan dibuat adalah sebagai berikut:

a) Jika waktu deteksi rotary encoder singkat dan putaran motor lambat hasilnya pada kuadran I

b) Jika waktu deteksi rotary ecoder sedang dan putaran motor sedang hasilnya pada kuadran II

c) Jika waktu deteksi rotary encoder lama dan putaran motor cepat maka hasilnya pada kuadran III

a. Software Aplikasi

c. Penalaran (Inference)
$[\mathrm{R} 1] \alpha 1=0 \quad$ rules $=20$ 


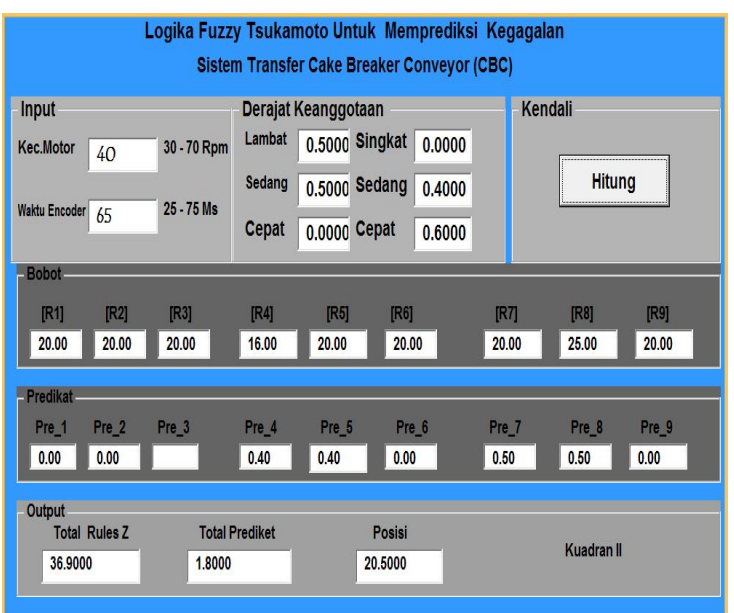

Gambar 11. Software aplikasi deteksi kegagalan system transfer cake breaker conveyor.

Hasil perhitungan software aplikasi dengan perhitungan manual memdapatkan hasil yang sama yaitu 20,50 Meter tepat pada posisi kuadran II. Apakah logika fuzzy dengan inferensi Tsukamoto dapat memberikan hasil sesuai dengan harapan dasar control deteksi putusnya asscrew pada CBC.

6. Data Analisis Penentuan Kuadran

Untuk pengujian lebih detail dilakukan ujicoba data menggunakan 9 data sebagai berikut:

Tabel 2. Uji data penentuan kuadran

\begin{tabular}{cccc}
\hline No & $\begin{array}{l}\text { Kecepatan } \\
\text { (CBC) }\end{array}$ & $\begin{array}{l}\text { Waktu Deteksi } \\
\text { Rotary Encoder }\end{array}$ & $\begin{array}{l}\text { Prediksi } \\
\text { Output }\end{array}$ \\
\hline 1 & 35 & 26 & KI \\
\hline 2 & 40 & 27 & KI \\
\hline 3 & 55 & 28 & KI \\
\hline 4 & 36 & 40 & KI \\
\hline 5 & 45 & 45 & KII \\
\hline 6 & 60 & 55 & KII \\
\hline 7 & 40 & 60 & KII \\
\hline 8 & 55 & 65 & KIII \\
\hline 9 & 65 & 68 & KIII \\
\hline
\end{tabular}

Penentuan kuadran pada titik putus nya CBC sebagai berikut:

a. Nilai $(10<=$ Kuadran I $<18)$

b. Nilai $(18<=$ Kundran II $<22)$

c. Nilai $(22<=$ Kuadran III $<30)$
Tabel 3. Hasil uji data penentuan kuadran

\begin{tabular}{ccccc}
\hline No & $\begin{array}{c}\text { Kecepatan } \\
(\mathrm{CBC})\end{array}$ & $\begin{array}{c}\text { Waktu } \\
\text { Rotary } \\
\text { Encoder }\end{array}$ & $\begin{array}{c}\text { Prediksi } \\
\text { Output }\end{array}$ & $\begin{array}{c}\text { Hasil } \\
\text { Output }\end{array}$ \\
\hline 1 & 35 & 26 & KI & 14,1981 \\
\hline 2 & 40 & 27 & KI & 15,6345 \\
\hline 3 & 55 & 28 & KI & 14,9597 \\
\hline 4 & 36 & 40 & KI & 16,1875 \\
\hline 5 & 45 & 45 & KII & 18,9821 \\
\hline 6 & 60 & 55 & KII & 20,5714 \\
\hline 7 & 40 & 60 & KII & 19,5000 \\
\hline 8 & 55 & 65 & KIII & 22,8167 \\
\hline 9 & 65 & 68 & KIII & 23,8727 \\
\hline
\end{tabular}

7. Hasil Pengujian

Dapat diambil kesimpulan dari Tabel 2 dan Tabel 3 bahwa prediksi dan hasil perhitungan tersebut hasilnya sesuai dan berbanding lurus dengan rules yang telah ditetapkan.

\section{KESIMPULAN}

Kesimpulan yang dapat diambil dari pengolahan data penentuan titik gagalnya system transfer cake breaker conveyor dengan memperhatikan kondisi putaran motor cbc dan waktu deteksi dari rotary encoder dapat disimpulkan bahwa :

1. Bahwa secara perhitungan dan implementasi menggunakan aplikasi visual basic Logika Fuzzy Tsukamoto dapat memprediksi titik kegagalan pada sistem transfer Cake Breaker Conveyor (CBC)

2. Dari hasil pengujian terhadap model prototype bahwa perubahan panjang dan pendeknya As-Screw Conveyor berpengaruh terhadap variabel input hukum kelembaman(momen inertia)

3. Untuk implementasi lebih lanjut diharapkan logika Fuzzy Tsukamoto dapat memprediksi putusnya Miniature Cake Breaker Conveyor pada Kuadran I,II dan III dengan nilai yang presisi. 


\section{DAFTAR PUSTAKA}

[1]. Adhar, C., Sumarlan, S. H., \& Nugroho, W. A. (2015). Rancang Bangun Metering Device Tipe Screw Conveyor dengan Dua Arah Keluaran untuk Pemupukan Tanaman Tebu, 4(1), 1-10.

[2]. Kimia, J. T., Teknik, F., \& Surabaya, U. (n.d.). DENGAN PROSES HIDROLISIS, 5 .

[3]. Okafor, B. E. (2015). Development of Palm Oil Extraction System. International Journal of Engineering and Technology, $5(2), 68-75$.

[4]. Rohayani., H. (2015). Fuzzy Inference System Dengan Metode Tsukamoto Sebagai Penunjang Keputusan Produksi (Studi Kasus: PT. Talkindo Selaksa Anugrah). Jurnal Sistem Informasi (JSI), 7(1), 753-764.

[5]. Santanu Chakarborthy1. (2014). Product Design of Semi Flexible Screw Conveyor \n. IOSR Journal of Mechanical and Civil Engineering (IOSR-JMCE), 11(5),01-03. https://doi.org/10.1109/ICIP.1997.632133

[6]. Santoso, A., Puspita, Eru Kom, S. T. M., \& Akbar, Ressa Ccna, S. T. (2010). Argometer pada Ojek Motor Berbasis Mikrokontroler. Politeknik Elektronika Negeri Surabaya-ITS. Retrieved from https://www.pens.ac.id/uploadta/download mk.php?id=1845

[7]. Wable, M. M., \& Kurkute, V. K. (2015). Design and Analysis of Screw Conveyor at Inlet of Ash / Dust Conditioner, 5(5), 291296. 